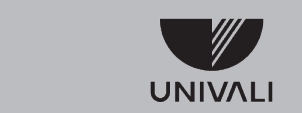

UNIVERSIDADE DO VALE DO ITAJAí

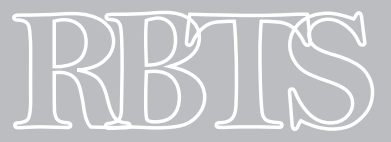

Revista Brasileira de Tecnologias Sociais
* Mestre em Gestão de Políticas Públicas pela Universidade do Vale do Itajaí. Bibliotecária da Universidade Federal do Paraná.

**Doutor em Sociologia Política pela UFSC. Coordenador do Mestrado Profissional em Gestão de Políticas Públicas da UNIVALI.
Revista Brasileira de Teenologias Sociais, v.1, n.1

doi: $10.1421 / 6 /$ rbts. 1.n1.p43-49

\section{Organização e informatização \\ e uma biblioteca comunitária}

\section{Organization and computing \\ or community library}

\author{
Maria Josefina Klock*; Flávio Ramos**
}

Resumo: O presente artigo tem por objetivo apresentar a sistematização, a organização e a informatização da Biblioteca Comunitária da Vila das Torres - Curitiba (PR), visando promover na comunidade local o acesso à informação, à cultura, ao lazer e à educação. Por outro lado, a pesquisa visa divulgar o trabalho de produto ou processo que possa ser caracterizado como tecnologia social. A organização e a informatização foram realizadas entre setembro de 2010 e maio de 2011 . Utilizaram-se a Classificação Decimal Universal (CDD) e a Tabela de Cutter-Sanborn e, para a informatização, o gerenciador de bibliotecas e os centros de informações e/ou documentação, o software Personal Home Library (PHL) - ambiente monousuário - gratuito. Contou com uma bibliotecária no preparo técnico, dois auxiliares e supervisão da autora da pesquisa, também profissional da área. Trata-se de uma pesquisa qualitativa de cunho exploratório e bibliográfico. Os resultados são descritivos, por meio de gráficos e fotografias. Concluiu-se que a intervenção técnica realizada na Biblioteca Comunitária da Vila das Torres modificou o ambiente, o acervo e os serviços. O novo cenário, organizado e informatizado, deixa para trás o clima de depósito, com estantes lotadas de livros sem nenhum arranjo e renasce pronto para colocar o livro nas mãos dos usuários.

Palavras-chave: Tecnologia Social. Biblioteca Comunitária. Ação social.

Abstract: This article presents the systematization, organization and computerization of the Biblioteca Comunitária da Vila das Torres [Vila das Torres Community Library] in Curitiba (PR), seeking to promote access to information, culture, leisure and education within the local community. The research also seeks to divulge the work of a product or process that can be characterized as social technology. The organization and computerization were carried out from September 2010 to May 2011. The Universal Decimal Classification system (UDC) and the Cutter-Sanborn table were used, and for the computerization, the library manager and information and/or documentation center manager software Personal Home Library (PHL) was used, a free of charge singleuser environment. A librarian was involved in the technical preparation, along with two assistants, with the supervision of the author of the research, also a professional in the area. It is a qualitative research of an exploratory and bibliographic nature. It was concluded that the technical intervention carried out at the Biblioteca Comunitária da Vila das Torres altered the environment, the archive, and the services. The new scenario, organized and computerized, moved away from the climate of a book deposit with shelves laden with books that were not properly organized, and was reborn, ready to place the book in the users hands.

Keywords: Social technology. Community Library. Social Action. 


\section{INTRODUÇÃO}

Inserção e inovação social constituem o foco deste artigo, que apresenta relatos de experiência de intervenção social, tendo como objetivo divulgar experiências práticas que resultaram em formas de inserção social que atendam a demandas sociais específicas, estudadas, validadas e que colaborem com a transformação da qualidade de vida de determinada comunidade.

Afinal, as bibliotecas comunitárias são espaços públicos surgidos em comunidades carentes, geralmente criadas por pessoas da própria comunidade, preocupadas com a exclusão social (ALMEIDA JUNIOR, 1997; MACHADO, 2008). Ao criar esses espaços, elas buscam basicamente estimular e promover o hábito de leitura, contribuir para minimizar o analfabetismo e suprir as necessidades informacionais, visando às mudanças positivas na comunidade. Costa (2011, p. 5) afirma que o objetivo dessas bibliotecas é “[ [...] proporcionar a leitura a toda a comunidade e dar uma contribuição ao indivíduo, integrando-o no contexto sócio, político e cultural, com condições elevar o nível da população […”.".

A Biblioteca Comunitária da Vila das Torres se enquadra nessa categoria e se destaca pelo histórico de sua criação, trajetória, agentes sociais envolvidos e comunidade a qual pertence: um local carente, referência no tráfico de drogas e espaço dos carrinheiros, pessoas que recolhem papéis e outros materiais e vendem para reciclagem.

Desde a sua criação, em 2009, a Biblioteca Comunitária da Vila das Torres chamou atenção dos meios de comunicação, que passaram a divulgá-la, sensibilizando a autora desse texto, a qual se tornou colaboradora e promoveu uma intervenção técnica, relatada na dissertação de mestrado "Biblioteca Comunitária da Vila das Torres - Curitiba: espaço sustentável de inclusão social" (KLOCK, 2011). Essa pesquisa forneceu os subsídios para o presente artigo, cujo objetivo é apresentar a sistematização, a organização e a informatização da Biblioteca Comunitária da Vila das Torres, para facilitar à comunidade local o acesso à informação, à cultura, ao lazer e à educação. Para tanto, se tornou imprescindível avaliar o acervo, as necessidades da comunidade e o perfil dos usuários, bem como providenciar um software adequado e treinamento do pessoal. Ampliar a coleção infantil e infantojuvenil, realizar a seleção e o processamento técnico do material constituíram etapa transformadora, acompanhada, principalmente, pelas crianças, usuários constantes e foco da biblioteca.

A pesquisa realizada é de cunho exploratório e bibliográfico, natureza aplicada e abordagem qualitativa. Utiliza-se da investigação bibliográfica e documental para o seu embasamento e os resultados são apresentados de forma descritiva, por meio de gráficos e fotografias.

O tema é considerado relevante para a biblioteconomia, em função do reduzido número de trabalhos sobre bibliotecas comunitárias no Brasil; e ganha importância na área social, por relatar ações desenvolvidas em comunidade cuja população carece de recursos que possibilitem a sua inclusão social.

\section{A Vila das Torres e a biblioteca COMUnitária: SUA CRIAÇÃO, OBJETIVOS E TRAJETÓRIA}

A Vila das Torres é uma área central da Cidade de Curitiba, a 2 km do centro, no perímetro do Bairro Prado Velho. Inicialmente conhecida como Favela do Capanema, depois Vila Pinto e, a partir de 1995, Vila Torres (COHAB-CT, 2005). Entretanto, para a Associação dos Moradores, seu nome é Vila das Torres. Conforme dados fornecidos pela Companhia de Habitação Popular de 
Curitiba (COHAB-CT) e divulgados por Fernandes (2011), a Vila das Torres ocupa uma área de 199,4 mil $\mathrm{m}^{2}$, possui uma população de 8,5 mil pessoas, 2.480 famílias, 1.028 domicílios e a renda familiar é de dois a três salários mínimos. O porcentual de alfabetizados é de $79,8 \%$ e 20,2\% não frequentaram a escola.

A economia da Vila gira em torno da reciclagem de materiais colhidos na cidade. Barros (2008), em artigo no Jornal Comunicação - Curso de Jornalismo UFPR -, afirma que “dos quase nove mil moradores da Vila estima-se que 1,5 mil sejam catadores de papel e que $70 \%$ da comunidade tenha sua renda ligada à coleta de material reciclável”.

A Biblioteca Comunitária surgiu no interior da Vila das Torres, foi idealizada e criada por um dos moradores que, ao divulgar a ideia, obteve a colaboração de outras sete pessoas, das quais cinco também são moradoras da comunidade e duas externas. Assim, a iniciativa de um cidadão empreendedor e criativo transformou-se numa ação coletiva.

A organização da Biblioteca Comunitária da Vila das Torres ocorreu em parte quando de sua informatização, uma vez que os modernos sistemas de gerenciamento de bibliotecas facilitam este trabalho.

Dentre os vários softwares para informatização de bibliotecas disponíveis no mercado, optou-se pelo Personal Home Library (PHL), uma aplicação web desenvolvida para gerenciar coleções, serviços de bibliotecas e centros de informações, disponibilizado, de forma gratuita, para estações monousuárias. Na página eletrônica do PHL, seu criador Oliveira (2011) explica:

Foi concebido como uma alternativa moderna e eficiente às bibliotecas e usuários com poucos recursos (financeiro e de pessoal) e que pretendem organizar suas coleções, automatizar rotinas e serviços e/ou disponibilizar e compartilhar seus catálogos através da Web.

O PHL utiliza interface de uso intuitivo, não requerendo de seus usuários nenhum tipo especial de treinamento.

O padrão do registro utilizado pelo PHL se baseia no formato UNISIST/Unesco [...] proporciona aos bibliotecários a descrição eficiente e precisa de qualquer tipo de informação independentemente de seu suporte.

Essas características motivaram a escolha desse software, que é compatível com qualquer sistema operacional: Windows, Linux, FreeBSD, HP-UX e outros e, navegadores conhecidos, como o Netscape, o Mozilla, o Opera, o Internet Explorer e outros. O PHL funciona em ambiente de rede, mas na Biblioteca Comunitária da Vila das Torres implantou-se a versão gratuita, com interface monousuário, em função das características da comunidade e dos parcos recursos financeiros para o seu licenciamento.

Procurou-se conscientizar os dirigentes da Biblioteca Comunitária das alterações em decorrência da organização e da informatização. Enfatizaram-se pontos como redução do acervo em função da seleção do material bibliográfico, necessidade de equipamento, mudança no layout da sala, benefícios e cuidados necessários tanto na fase de realização dos trabalhos como na posterior e perfil das pessoas para o atendimento.

A realização da intervenção técnica contou com a coordenação da autora da pesquisa, profissional da área, e mais três pessoas, sendo uma bibliotecária para a seleção e para o processamento técnico do material e dois auxiliares para as atividades diversas. 
Após a realização dos procedimentos iniciais da pesquisa, o diagnóstico, a campanha de arrecadação de material bibliográfico, a apresentação do projeto aos dirigentes, realizou-se a Missão da Biblioteca, o Regulamento Interno e a Política de Formação e Desenvolvimento de Coleções.

Os trabalhos com o acervo iniciaram-se com a separação do material por tipo e por assunto, visando à seleção, que foi norteada pela Política de Formação e Desenvolvimento de Coleções, conforme Klock (2011, p. 175-181).

De dezembro de 2010 a março de 2011 os dirigentes da Biblioteca Comunitária receberam várias caixas de livros e outros materiais especiais, dos quais separaram apenas 780 livros de diversas áreas e 35 itens referentes ao material especial, para posterior seleção pela equipe responsável por essa atividade técnica.

Ressalta-se que a seleção dos livros para o público infantil, infanto-juvenil e material especial contou com a participação da atendente da biblioteca, de dois dirigentes e de uma pedagoga voluntária, que na época realizava atividades com os usuários infantis. Essas pessoas conhecem as crianças, as suas aptidões, os estágios em termos de alfabetização e leitura, bem como o seu meio familiar e social, contribuindo para a formação de uma coleção infantil adequada. A organização simplificada desse material ocorreu em abril, com o material separado por tipo, relacionado e disposto nas estantes para facilitar o seu uso e o seu controle.

Os livros didáticos e os materiais especiais ficaram separados para inserção na base do PHL nos meses seguintes. O Quadro 1 apresenta os períodos em que foram realizadas as ações.

O cronograma estabelecido no projeto para a organização e para a informatização da Biblioteca Comunitária previa o seu término para março de 2011 , entretanto atrasou devido às peculiaridades existentes na Vila.

A concentração maior de livros ocorre na década de 1990, seguida pela de 2000, portanto material bibliográfico publicado nas últimas décadas. Muitos desses livros são recebidos ou encontrados no lixo ainda com a embalagem plástica, comprovando que não foram lidos. Os dicionários, em sua maioria, datam da década de 1990, assim como as enciclopédias, cuja doação tornou-se comum. Em geral, atribui-se à Internet o declínio de sua manutenção, entretanto essas fontes de conhecimento não são substituídas pelas informações disponibilizadas na web. Na Biblioteca Comunitária, esses materiais são procurados principalmente para as pesquisas escolares.

A intervenção técnica realizada na Biblioteca Comunitária da Vila das Torres alcançou o seu objetivo: facilitar a interação entre material bibliográfico e usuário e otimizar os serviços oferecidos. Porém o usuário não tem acesso ao computador da Biblioteca Comunitária para consultar o catálogo informatizado, ou seja, o PHL, sendo esse procedimento restrito ao pessoal da Biblioteca. Assim, o usuário expõe a sua necessidade informacional e a consulta é formulada pela atendente, para verificar se o material desejado consta no acervo, é encontrado e disponibilizado para a pesquisa e/ou empréstimo.

O empréstimo é informatizado. Para realizar o cadastro, o usuário deve apresentar o Cartão de Identidade e o comprovante de endereço. É estipulado um prazo para a devolução da obra, entretanto, se o livro retorna com atraso, o usuário é somente advertido, não se aplicando penalidade. Nesse sentido, faz-se necessário que as pessoas envolvidas no atendimento aos usuários, além de conhecer todos os procedimentos, saibam também se utilizar de práticas flexíveis, 
condizentes com a realidade local, para cativar e manter o leitor. Assim, é positivo que pessoas da comunidade sejam treinadas para o atendimento da biblioteca, mesmo que haja voluntários externos, pois as pessoas da comunidade se conhecem, o que encoraja o diálogo, a permanência por mais tempo no local e também o seu retorno.

Quadro 1 - Períodos e Respectivas Ações Realizadas para a Organização e a Informatização da Biblioteca Comunitária

\begin{tabular}{|c|c|}
\hline \multicolumn{2}{|c|}{$\begin{array}{c}\text { ORGANIZAÇÃO E INFORMATIZAÇÃO DA BIBLIOTECA } \\
\text { COMUNITÁRIA VILA TORRES }\end{array}$} \\
\hline PERÍODO & AÇõES \\
\hline Outubro-2010 & $\begin{array}{l}\text { - Realização da Missão, do Regimento Interno e da } \\
\text { Política de formação e Desenvolvimento de Coleções; } \\
\text { - Reuniões com os dirigentes com vistas à informatização } \\
\text { do acervo; } \\
\text { - Elaboração do projeto de informatização: } \\
\text { - Levantamento dos softwares gerenciadores de bibliotecas, } \\
\text { gratuitos, disponíveis. }\end{array}$ \\
\hline Novembro-2010 & $\begin{array}{l}\text { - Análise dos softwares selecionados; } \\
\text { - Levantamento do material e do pessoal necessário: um } \\
\text { bibliotecário e dois auxiliares; } \\
\text { - Contratação da equipe; } \\
\text { - Realização de reunião para apresentação do PHL à } \\
\text { equipe; } \\
\text { - Definição das estratégias para a realização dos } \\
\text { trabalhos; } \\
\text { - Compra dos materiais: etiquetas, papel sulfite, cartucho } \\
\text { para impressora, papel contact, luvas, máscaras e outros } \\
\text { materiais necessários; } \\
\text { - Apresentação da equipe contratada aos dirigentes e à } \\
\text { atendente da Biblioteca Comunitária. }\end{array}$ \\
\hline $\begin{array}{l}\text { Dezembro-2010 } \\
\text { a abril-2011 }\end{array}$ & $\begin{array}{l}\text { - Realização das atividades técnicas: seleção do material } \\
\text { bibliográfico, separação por tipo, classificação e inclusão } \\
\text { dos dados dos livros na base bibliográfica do PHL; } \\
\text { - Treinamento do pessoal da biblioteca; } \\
\text { - Organização do acervo nas estantes. }\end{array}$ \\
\hline Maio-2011 & $\begin{array}{l}\text { - Sinalização das estantes; } \\
\text { - Atualização dos dados no PHL instalado na Biblioteca; } \\
\text { - Registro, mediante fotografia, do resultado da nova } \\
\text { organização da Biblioteca. } \\
\text { - Apresentação da biblioteca devidamente organizada aos } \\
\text { dirigentes da Biblioteca Comunitária; } \\
\text { - Orientação quanto à organização dos livros infantis, } \\
\text { gibis, material didático e os materiais especiais, CDs, } \\
\text { Fitas de vídeo VHS e fitas cassetes, não incluídos no PHL } \\
\text { nessa etapa. }\end{array}$ \\
\hline
\end{tabular}

Fonte: Elaborado pela autora (2011). 
Sob a coordenação dos dirigentes da Biblioteca Comunitária, o público infantil conta com atividades de apoio à alfabetização, à formação do hábito de leitura e outras práticas voltadas ao desenvolvimento intelectual das crianças. O público infanto-juvenil conta com reforço nas atividades escolares e na formação do hábito de leitura.

A Biblioteca Comunitária atende pela manhã e pela tarde, cumprindo o seu papel de mediadora e difusora do conhecimento.

\section{CONSIDERAÇÕES FINAIS}

A organização e a informatização da Biblioteca Comunitária da Vila das Torres iniciaram em setembro de 2010 e foram concluídas em maio de 2011, visando transformar o ambiente, o acervo e os serviços para facilitar e ampliar as possibilidades de acesso à informação. Acredita-se que o objetivo tenha sido alcançado, pois o novo cenário foi dotado de ferramentas para promover o encontro do leitor com o livro, esse instrumento indispensável na luta pela inclusão social.

Para a informatização, utilizou-se o software PHL, um moderno gerenciador de bibliotecas e centro de informação e/ou documentação, o qual, como desejo dos dirigentes da biblioteca e dos usuários, auxilia, informando se o livro desejado faz parte da coleção, sua localização na estante, o cadastro dos usuários, o empréstimo das obras, a renovação e a devolução com rapidez.

O acervo destinado ao público adulto e infanto-juvenil foi preparado tecnicamente, organizado e informatizado. A coleção destinada ao público infantil é igualmente organizada, possibilitando o seu acesso, o controle e o empréstimo. Os demais materiais - cadernos para colorir, jogos e outros do gênero, bem como os livros didáticos e o material especial - foram organizados e disponibilizados conforme as características e os mobiliários da biblioteca.

A expectativa pela intervenção técnica realizada consiste no crescimento da Biblioteca Comunitária da Vila das Torres como espaço dinâmico, de fácil acesso à informação e de integração da comunidade, em que o livro, pelos conhecimentos que transmite, contribua para formar um cidadão consciente e socialmente responsável.

\section{REFERÊNCIAS}

ALMEIDA JUNIOR, O. F. Bibliotecas públicas e bibliotecas alternativas. Londrina: UEL, 1997.

BARROS, L. Vila das Torres I - almoço digno para os carrinheiros. Jornal Comunicação: Jornal do laboratório do curso de jornalismo da UFPR. Curitiba, 14 jun. 2008. Especial - Curitiba como ela é. Disponível em: <http://www.jornalcomunicacao.ufpr.br/node/4121>. Acesso em: 22/01/2011.

COHAB-CT. Habitação: maior parte dos moradores da Vila das Torres tem casa própria. Curitiba, 2005.

COSTA, M. de F. O. A informação e o exercício da cidadania. Disponível em:

<http://www.dci.ufc.br/fatimacosta/f_costa_publ.html>. Acesso em: 02/01/2011.

FERnAndes, J. C. O armistício da Vila Torres. Gazeta do Povo, Curitiba, 18 abr. 2011. Vida e Cidadania, Comunidade. Disponível em: <http://www.gazetadopovo. com.br/vidaecidadania/conteudo. phtml?id=1117205>. Acesso em: 25/05/2011. 
KLOCK, M. J. Biblioteca Comunitária da Vila das Torres - Curitiba: espaço sustentável de inclusão social. 182 f. Dissertação (Mestrado Profissional em Gestão de Políticas Públicas) - Centro de Ciências Socais e Jurídicas, Universidade do Vale do Itajaí, Itajaí, 2011.

MACHADO, E. C. Bibliotecas comunitárias como prática social no Brasil. 184 f. Tese (Doutorado em Ciência da Informação) - Escola de Comunicações e Artes, Universidade de São Paulo, São Paulo, 2008.

OLIVEIRA, E. M. S. de. PHLCElysio. Disponível em: <http://www.elysio.com.br/>. Acesso em: 05/05/2011. 